RESEARCH ARTICLE

\title{
Flame retardancy of chlorinated elastomers
}

\author{
Nicholas T. Fernando and Sudantha S. Liyanage* \\ Department of Chemistry, Faculty of Applied Science, University of Sri Jayewardenepura, Gangodawila, Nugegoda.
}

Revised: 19 August 2008 ; Accepted: 22 September 2008

\begin{abstract}
Elastomers, that contain halogens in their structure have been found to be resistant to flame. Industry uses many elastomers containing halogens, particularly chlorine, in the structure in varying proportions. Traditionally, chlorinated polymers such as polychloroprene (CR), containing different number of chlorine atoms in the structure, are used as flame resistant polymers in industry. However, as the polymer usage in day to day activities for domestic, office and particularly in the transport industry is on the increase, eliminating the fire hazard of polymers is currently of great concern. Hence, there is an absolute need to develop polymers with better flame resistance.
\end{abstract}

Three elastomers namely polychloroprene(CR) chlorinatedpolyethylene(CM) and epichlorohydrene(ECO) with the same content of chlorine were used in this study. Two popular flammability tests were used and they are the UL 94 testing method developed by the Underwriters Laboratory and the LOI test. The minimum quantity of oxygen required for combustion were measured according to the relevant BS and ASTM standards. Tensile strength and hardness tests were performed in accordance with the relevant BS standards.

According to the results observed in the UL 94 testing method, all three elastomers were rated for vertical burn as V0. Values obtained from the LOI test clearly shows that CM has a higher value. When comparing mechanical properties, even though $\mathrm{CR}$ has the highest tensile strength, CM has the highest hardness. According to our results $\mathrm{CM}$ has low flammability and better mechanical properties than the other two elastomers.

Keywords: Chlorinated polymers, elastomers, flame retardancy, flammability, LOI test

\section{INTRODUCTION}

Flame retardant elastomers are very important in various applications. It is particularly important in the building and transport industries due to safety reasons. Prior to 1977, elastomer flammability was reviewed extensively by Fabris and Sommer ${ }^{1,2}$. Demand for flame resistant materials including elastomers has rapidly grown in the last three decades ${ }^{3}$. Many tragic accidents have been caused by flammable materials. Elastomers are known to have particular burning characteristics with heavy smoke. Various chemicals and additives have been developed to reduce flammability and to suppress smoke generation. The smoke can be fatal by lowering the level of oxygen available for respiration. Many European countries have stipulated strict specifications with regard to flammability of elastomers used in transport and buildings, especially in interiors. However, in achieving low flammability the physical properties should not be compromised ${ }^{4}$.

Three potential elastomers polychloroprene (CR), chlorinatedpolyethylene (CM), epichlorohydrene (ECO) were selected based on their chlorine content. Chloroprene rubber is a traditional elastomer used as a flame retardant ${ }^{5}$. It has also been used widely as an oil resistant elastomer. The preferable curing system for CR at present involves thiourea and lead, which are hazardous to health ${ }^{6,7}$. The same curing system was used for ECO in many applications. It is desirable to investigate whether their flame retardancy is affected by using an alternative cure system. For CM, the only viable cure system is peroxide ${ }^{8}$.

Two popular flammability tests were used in the project. The UL 94 testing method developed by Underwriters Laboratory in order to find the burning characteristics of solid plastics was used to find the burning behaviour of the three developed elastomers? The minimum quantity of oxygen required for combustion was determined by the LOI test which was carried out in accordance with the ASTM D2863 ${ }^{10,11}$. The results of the given tests were compared with the tensile strengths. Tensile strength and hardness tests were performed in accordance with the relevant BS standards ${ }^{12}$. 


\section{METHODS AND MATERIALS}

Three base polymers were used for this study namely, epichlorohydrine (ECO), chlorinated Polyethylene (CM) and polychloroprene (CR). CM was supplied by Omya UK Ltd. (Surrey, England) under the trade name of Tyrin 3630E. ECO was supplied by Zeon Chemicals, UK in the form of $25 \mathrm{~kg}$ bales under the trade name of Hydrin H55. CR was supplied by DuPont Dow elastomers (USA) under the trade name of Neoprene WRT. Intrinsic properties of these elastomers are summarised in the Table 1. Furthermore, Struktol 60NS and n-butyldithiocarbamate (NBC), aromatic hydrocarbons were used as processing aids for the compounds.

Table 1: Intrinsic properties of base materials

\begin{tabular}{lccc}
\hline Properties & $\begin{array}{c}\text { CR } \\
\text { (Neoprene } \\
\text { WRT) }\end{array}$ & ECO & CM \\
\hline Chlorine content $(\%$ by weight) & $36 \%$ & $36 \%$ & $36 \%$ \\
Mooney viscosity $\left(\mathrm{ML} 1+4100^{\circ} \mathrm{C}\right)$ & $41-51$ & $50-60$ & $*$ \\
Specific gravity $\left(\mathrm{g} / \mathrm{cm}^{3}\right)$ & 1.25 & 1.1 & 1.3 \\
\hline
\end{tabular}

*Not specified by producer

The flame resistant chemicals used in this study were antimony oxide under the trade name of Garoflam $S B$ 96 DINP, zinc borate under the trade name Zinborel and magnesium hydroxide under the trade name of Magnafin H10 supplied by Omya UK Ltd. The vulcanisation agents used for these elastomers are as follows. For ECO \& CR ethylene thiourea (ETU), $\mathrm{MgO}$ and $\mathrm{ZnO}$ system, and $\mathrm{CM}$ peroxide curing system used with dicumyl peroxide (DCP).

Formulations: Formulations were especially designed to use the same level of flame resistant chemicals in each compounding. This action helps to identify the unique flammability properties of elastomers itself. Proposed formulations are shown in Table 2. Formulation of the CM compound with 95pphr of CM and 5pphr of SBR is for better incorporation of the chemicals.

Compounding and vulcanisation: Three different techniques were used to compound the three elastomers due to the difference in structure and properties. For polycloroprene rubber, the entire compounding process was carried out on a 22 " two roll mill operating at a friction speed of $1.25: 1.00$, at temperature $\sim 50-55^{\circ} \mathrm{C}$. The mixing procedure was carried out according to the Appendix No 1. The prepared sheet was secured in a polythene sheet and stored in a fridge.
Table 2: Formulations for proposed compounds

\begin{tabular}{lccc}
\hline & ECO & CM & CR \\
\hline Epichlorohydrine (ECO) & 100 & - & - \\
Chlorinatedpolyethylene (CM) & - & 95 & - \\
Polychloroprene rubber (CR) & - & - & 100 \\
Styrenebutadiene rubber (SBR) & - & 5 & - \\
Carbon black & 10 & 10 & 10 \\
Calcined clay & 40 & 40 & 40 \\
Zinc borate & 10 & 10 & 10 \\
Lithage (90\%) & 5 & - & 5 \\
Antimony oxide & 5 & 5 & 5 \\
Magnafin (flame retardant) & 10 & 10 & 10 \\
Elthylenetriurea (75\%) & 2 & - & 0.5 \\
NBC (NDBC-antioxidant) & 2 & - & 2 \\
Stearic acid & 1 & - & 1 \\
Zinc stearate & 1 & - & 1 \\
Struktol 60 NS & 1 & - & 1 \\
Magnesium oxide & - & 5 & 4 \\
Zinc oxide (85\%) & - & - & 5 \\
Dicumyl peroxide (DCP) & - & 9 & - \\
Flectol H & - & 2 & - \\
\hline & 187 & 191 & 194.5 \\
\hline
\end{tabular}

Preparation of eco base mix: The base formulation for the ECO mix is given in the Table 2. All ingredients were weighed to within $0.1 \mathrm{~g}$ of mass specified. Master batch preparation was carried out in the internal mix for ECO, carbon black and calcined clay. A $2500 \mathrm{~cm}^{3}$ Francis Shaw (Manchester, UK) intermix was used for the mixing cycle. This internal mixer was set to operate at a rotor speed of 44 cycles min $^{-1}$ under a ram pressure of $\sim 0.70 \mathrm{MPa}$. The masterbatch was prepared under the above condition according to the time schedule outlined in Appendix No 2.

At the end of the schedule, the masterbatch was cooled and refined on a $0.45 \mathrm{~m}$ two roll mill operating at even speed of $15 \mathrm{rev} . \mathrm{min}^{-1}$. The sheeted masterbatch was secured in a polythene and kept in a cold dry place. Flame resistant pigments and curing agents were incorporated on a laboratory 22 " two roll mill under the same conditions described in Appendix 1. The procedure was carried out according to Appendix 3.

Preparation of CMmasterbatch: Masterbatch preparation of CM was carried out in an oil heated chamber combined with a Plasticorder machine. The $300 \mathrm{~cm}^{3}$ chamber was heated up to $\sim 130-160{ }^{\circ} \mathrm{C}$ for easy fusion of the $\mathrm{CM}$ powder. Rotor speed was initially set as $40 \mathrm{rpm}$ and reduced to $10 \mathrm{rpm}$ during the mixing due to high torque. Appendix 4 outlines the mixing cycle procedure. 
Preparation of CM vulcanizate: The procedure was carried out using the same two roll mill mentioned above. Initially, few pieces of SMR 10 rubber were passed through the two rollers for cleaning purpose. Thereafter, the gap of the nip rollers was adjusted to $1 / 8$ of inch and followed the procedure given in Appendix 5 .

Determination of vulcanisation characteristics: The determination of vulcanisation characteristics was carried out on a Monsanto Oscillating Disc Rheometer (ODR) 100S type. The amplitude of the machine was $\pm 3^{0}$ arc. Results obtained are given in Table 3. According to the results obtained from ODR test vulcanisation time was adjusted to $\mathrm{T}_{95}$. A Bradley and Tutron (Kiddermaster, UK) double daylight steam press was used for the moulding process. For each mix several test pieces of the size $130 \pm 1 \mathrm{~mm}$ long $10.0 \pm 1 \mathrm{~mm}$ wide and $1.75 \pm 0.2 \mathrm{~mm}$ thick were produced. These test pieces were stored in a cold dry place for $16 \mathrm{~h}$ for homogenisation.

UL 94 flammability testing: The Underwriters Laboratories have developed a series of flammability tests, all designated under UL 94. For plastic and rubber to receive a certain UL rating, it must pass certain criteria of a test. The different ratings are outlined below in Table $3{ }^{10}$.

The apparatus was selected according to the Underwriters Laboratories specifications described in the UL 94 testing procedure. The experiment was carried out in the London Metropolitan University Rubber Testing Laboratory. The method for determining the classification of UL 94 is clearly indicated in the above mentioned document.

Oxygen index test (ASTM D 2863): The Oxygen index tests mean that minimum concentration of oxygen in a pure oxygen /nitrogen environment that is necessary for the sample to maintain combustion. The sample is hung vertically in a special chamber, and then ignited. The oxygen concentration is then reduced until the combustion is just maintained. The Limiting Oxygen Index (LOI) represents this percentage of oxygen.

The experiment was conducted at the Loughborough University, Leicestershire, UK. The apparatus was manufactured by Fire Testing Technology, Sussex , UK. The testing unit has been designed to be compact for efficient use in a standard fume cupboard. The unit gives continuous digital readout of oxygen concentrations in the test atmosphere to facilitate quick settings of test concentration. Stabilized oxygen percentages are read from the digital readout and no additional flow adjustments are required.

Determination of physical properties: Tensile strength and hardness of the selected vulcanites were tested according to the relevant BS standards. Testing for the tensile strength was carried out according to the BS 903 A26, A2 ${ }^{12}$ standards using the Instron 1122 tensile testing machine.

\section{RESULTS \& DISCUSSION}

Results obtained for different properties are tabulated in Table 4, Table 5, Table 6 and Table 7. Comparisons of properties of three polymers are given in Figure 1.

According to the flammability testing results Chlorinated Polyethylene (CM) vulcanite shows the highest LOI index value (Figure 1). Meanwhile, UL 94 testing for the same vulcanite shows the promising result of categorising as $\mathrm{V}-0$. However, comparing the tensile strength, selected vulcanites did not show satisfactory results.

Table 3: UL 94 flammability ratings description

\begin{aligned} \hline \multicolumn{1}{c}{ Rating } & \multicolumn{1}{c}{ Description of action } \\ \hline 5VA & $\begin{array}{l}\text { Burning stops within } 60 \text { seconds after five applications of five seconds each of a flame (larger than that used in Vertical } \\ \text { burn testing) to a test bar. Test specimens may not have a burn-through (no hole). }\end{array} \\ 5 \mathrm{VB} & \begin{array}{l}\text { Burning stops within } 60 \text { seconds after five applications of five seconds each of a flame (larger than that used in Vertical } \\ \text { burn testing) to a test bar. Test specimens may have a burn-through (a hole). }\end{array} \\$ Surface burn & Burning stops within 10 seconds after two applications of ten seconds each of a flame to a test bar. No flaming drips \\ Vertical burn & are allowed. \\ V-1 & $\begin{array}{l}\text { Burning stops within } 60 \text { seconds after two applications of ten seconds each of a flame to a test bar. No flaming drips } \\ \text { are allowed. }\end{array} \\$ V-2 & $\begin{array}{l}\text { Burning stops within } 60 \text { seconds after two applications of ten seconds each of a flame to a test bar. Flaming drips are } \\ \text { allowed. }\end{array} \\$ Vertical burn & $\begin{array}{l}\text { Slow horizontal burning on a 3mm thick specimen with a burning rate less than 3"/min or stops burning before the 5" } \\ \text { mark. H-B rated materials are considered "self-extinguishing". }\end{array} \\$ Horizontal burn & \end{aligned}


Table 4: Vulcanisation characteristics of the chosen compounds

\begin{tabular}{|c|c|c|c|c|c|}
\hline & $\begin{array}{c}\mathrm{T}_{\mathrm{S} 2} \\
\text { Minutes }\end{array}$ & $\mathrm{T}_{95}$ Minutes & $\mathrm{T}_{99}$ Minutes & $\begin{array}{c}\mathrm{M}_{\mathrm{H}}-\mathrm{M}_{\mathrm{L}} \\
\mathrm{N}_{\mathrm{m}}\end{array}$ & $\begin{array}{c}\text { Temperature } \\
\mathrm{C}_{0}\end{array}$ \\
\hline Epichlorohydrene (ECO) & 1.44 & 41.59 & 59.55 & 80.9 & 170 \\
\hline Chlorinatedpolyethylene (CM) & 1.59 & 43.14 & 59.58 & 55.0 & 150 \\
\hline Polychloroprene rusder (CR) & 2.32 & 52.59 & 52.59 & 75.0 & 150 \\
\hline
\end{tabular}

Table 5: Results of the UL 94 test carried out according to the schedule

\begin{tabular}{|c|c|c|c|}
\hline Vulcanite & Sample No. & $\begin{array}{l}\text { Time taken to self extinguish } \\
\text { (seconds) }\end{array}$ & UL 94 classification \\
\hline \multirow[t]{5}{*}{ Epichlorohydrene (ECO) } & Sample 1 & 5 & \\
\hline & Sample 2 & 3 & \\
\hline & Sample 3 & 5 & $\mathrm{~V}-0$ \\
\hline & Sample 4 & 4 & \\
\hline & Sample 5 & 5 & \\
\hline \multirow[t]{5}{*}{ Chlorinatedpolyethylene (CM) } & Sample 1 & 2 & \\
\hline & Sample 2 & 2 & \\
\hline & Sample 3 & 3 & $\mathrm{~V}-0$ \\
\hline & Sample 4 & 2 & \\
\hline & Sample 5 & 2 & \\
\hline \multirow[t]{5}{*}{ Polychloroprene rubber(CR) } & Sample 1 & 10 & \\
\hline & Sample 2 & 9 & \\
\hline & Sample 3 & 9 & $\mathrm{~V}-0$ \\
\hline & Sample 4 & 8 & \\
\hline & Sample 5 & 10 & \\
\hline
\end{tabular}

Table 6: Results of LOI test

\begin{tabular}{|c|c|c|c|}
\hline Elastomer & Sample No. & $\begin{array}{c}\text { LOI Index } \\
\% \\
\end{array}$ & Mean \\
\hline \multirow{3}{*}{ Epichlorohydrene (ECO) } & 1 & 31.2 & \multirow{3}{*}{31.2} \\
\hline & 2 & 31.0 & \\
\hline & 3 & 31.5 & \\
\hline \multirow{3}{*}{ Chlorinatedpolyethylene (CM) } & 1 & 36.5 & \multirow{3}{*}{36.1} \\
\hline & 2 & 35.9 & \\
\hline & 3 & 36.5 & \\
\hline \multirow{3}{*}{ Polychloroprene (CR) } & 1 & 31.0 & \multirow{3}{*}{30.7} \\
\hline & 2 & 29.8 & \\
\hline & 3 & 31.0 & \\
\hline
\end{tabular}

Table 7: Physical properties of elastomers

\begin{tabular}{lcc}
\hline & Tensile Strength (MPa) & Hardness (IRHD) \\
\hline & 7.55 & 74.0 \\
Polychloroprene (CR) & 6.14 & 74.6 \\
Chlorinatedpolyethylene (CM) & 4.44 & 69.1 \\
Epichlorohydrene (ECO) & & \\
\hline
\end{tabular}




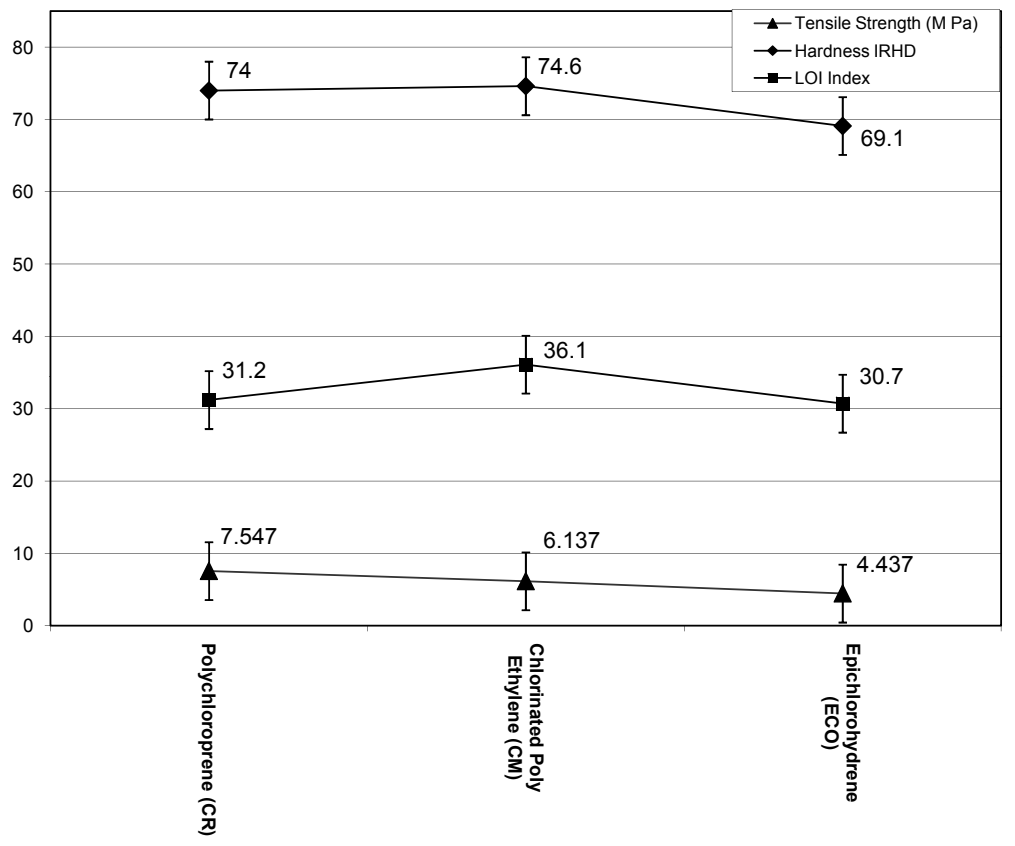

Figure 1: Comparison of properties of the three polymers

Flame retardancy occurs in polymers by free radical capture and char process. In free radical capture a chlorine radical is released from the elastomer when it is exposed to heat and this radical reacts with hydrogen radicals to form $\mathrm{HCl}$. This $\mathrm{HCl}$ reacts with $\mathrm{Sb}_{2} \mathrm{O}_{3}$ reagent which is incorporated into the polymer to produce $\mathrm{SbCl}_{3}$ and $\mathrm{H}_{2} \mathrm{O}$. $\mathrm{H}_{2} \mathrm{O}$ and $\mathrm{SbCl}_{3}$ will make the polymer fire retardant.

As shown in Figure 1 the elastomer that has the highest LOI value is CM. Even though the chlorine content in elastomers is the same, CM has the highest flame retardancy property, due to its structure. Unlike in other elastomers, in CM there are no double bonds. When there is a double bond there is a shift in the electron cloud of the bond which results in the formation of extra strength in between chlorine and carbon and this makes the bond between carbon and chlorine stronger than a normal single bond. Therefore, in CM the bound strength of $\mathrm{C}-\mathrm{Cl}$ is relatively lower than in other elastomers. When considering the free radical capture mechanism by which flame retardancy is induced, this property of the structure of CM is very important because it can produce a chlorine free radical more readily.

\section{CONCLUSION}

Hydrocarbons such as organic polymers are highly inflammable. Hence, much attention has been paid by scientists to make them fire resistant. Extensive work has been done during the past to improve flame resistance of elastomers. In this study we have used three elastomers
$(\mathrm{CR}, \mathrm{CM}, \mathrm{ECO})$ to increase their flame retardancy properties.

Comparing the mechanical properties and flammability properties, $\mathrm{CM}$ vulcanite gives promising results for both. The CM compound has low flammability and better mechanical properties than the other two elastomers. In addition, peroxide curing system used in the $\mathrm{CM}$ preparation is not categorised as hazardous to health. However the other two materials were cured using ETU (Ethylenethiourea) which is identified as carcinogenic by USEPA (US Environmental Protection Agency). Considering health \& safety factors the use of CM compound is more favourable than using $\mathrm{CR}$ or $\mathrm{ECO}$ as a flame retardant elastomer.

\section{Acknowledgement}

Authors wish to thank Dr Ahemed S. Farid from the London Metropolitan Polymer Centre for continuous support \& guidance throughout the project. Authors also wish to thank K.D. Arunashanthi and M.A.A. Wahab for support given during the tenure of research.

\section{References}

1 H.J. Fabis \& J.G. Sommer (1977). Flammability of elastomeric materials. Rubber Chemistry and Technology 50:523.

2 H.J. Fabis \& J.G. Sommer (1998). Flame retardent behaviour of chloroprene \& natural rubber vulcanizates with Antimony polymer. Journal of Applied Polymer Science. 68:6. 
3 Gilman J.W., Kashiwagi T., Mogan A.B. (2001). Recent Advances in Flame-retardant Polymer Nanocomposites, Fire and Materials. $7^{\text {th }}$ International Conference and Exhibition Proceedings, Inter science Communications Limited. January 22-24, 2001, San Antonio, TX, 273-283.

$4 \quad w w w$ flameretardent-online.com. (accessed on June 2004)

5 Lawson D.F. (1986). Recent development in the flammability of elastomeric materials. Rubber Chemistry \& Technology 59: 455.

6 Ethylene Thiourea, Report on Carcinogens, $10^{\text {th }}$ edition. U S Dept of Health \& Human services, Nat Toxicology Programme (Dec 2002).

7 U.S. Environmental Protection Agency, A Summary Overview of Health Effects Associated With Chloroprene. EPA $/ 600 / 8-85 / 011 F$.

Appendix 1: Mixing cycle of polychloroprene (CR) elastomer

\begin{tabular}{|c|c|c|}
\hline $\begin{array}{l}\text { Step } \\
\text { No }\end{array}$ & $\begin{array}{l}\text { Time } \\
\text { elapsed } \\
\text { Min }\end{array}$ & Action \\
\hline 1 & 0 & $\begin{array}{l}\text { Added } 300 \text { of CR and ran it until pellets } \\
\text { become a rubbery sheet, }\end{array}$ \\
\hline 2 & 4 & Added 15 of zinc oxide, \\
\hline 3 & 7 & Added half of the calcined clay, \\
\hline 4 & 10 & Added the remaining half of calcined clay, \\
\hline 5 & 14 & $\begin{array}{l}\text { Took out rubber as a sheet and wrapped the } \\
\text { carbon black around and rolled it on the mill, }\end{array}$ \\
\hline 6 & 18 & $\begin{array}{l}\text { Added the sweepings, cross cutting was performed } \\
\text { and mixed well, }\end{array}$ \\
\hline 7 & 20 & $\begin{array}{l}\text { Added all the other ingredients slowly and repeated } \\
\text { the step No } 6 \text {, }\end{array}$ \\
\hline 8 & 25 & $\begin{array}{l}\text { Took out as a sheet, and rolled it and passed it } \\
\text { through tight nip rollers for } 5 \text { times, }\end{array}$ \\
\hline 9 & 30 & Finally took out as a sheet. \\
\hline
\end{tabular}

8 Johnson P.S. (2001). Rubber Processing: an Introduction, Germany. Hanser Publishes, Munich.

9 ASTM Method D3801. Standard Test Method for Measuring the Comparative Burning Characteristics of Solid Plastics in a Vertical Position.

10 ASTM Method D2863 Measuring the Minimum Oxygen Concentration to Support Candle-Like Combustion of Plastics.

11 Nelson. M.I. (2001). A. Dynamic Systems Model of the Limiting Oxygen Index test, Department of Fuel and Energy, University of Leeds. UK.

12 BS 903: Part A 26 Determination of hardness, A36 Preparation of Test Pieces, A2 Measuring of Tensile Properties.
Appendix 2: Masterbatch mixing cycle for epicholrohydrene (ECO)

\begin{tabular}{lcl}
\hline $\begin{array}{l}\text { Step } \\
\text { No }\end{array}$ & $\begin{array}{c}\text { Time } \\
\text { elapsed } \\
\text { Min }\end{array}$ & Action \\
\hline 1 & 0 & Added ECO, \\
2 & 2 & Added $1 / 3$ of FEF carbon black, \\
3 & 4 & Added $1 / 3$ of calcined clay, \\
4 & 5 & Brushed down, \\
5 & 7 & Added further $1 / 3$ of carbon black, \\
6 & 9 & Added $1 / 3$ of calcined clay, \\
7 & 10 & Added remaining $1 / 3$ of carbon black, \\
8 & 11 & Added $1 / 3$ of calcined clay, \\
9 & 13 & Swept down, \\
10 & 15 & Dumped or discharged. \\
\end{tabular}

Appendix 3: Incorporation of chemicals into the ECO masterbatch on a two roll mill

\begin{tabular}{lcl}
\hline $\begin{array}{c}\text { Step } \\
\text { No }\end{array}$ & $\begin{array}{c}\text { Time } \\
\text { elapsed } \\
\text { Min }\end{array}$ & Action \\
\hline 1 & 0 & Added 300 masterbatch and ran it until it becomes a rubbery sheet, \\
3 & 4 & Added 4 of NBC, and 2 of stearic acid, \\
4 & 5 & Sweeping and cross cutting were performed four times on each side, \\
5 & 7 & Added two of zinc stearate, \\
6 & 14 & Took out rubber as a sheet and wrapped the carbon black around and rolled it on the mill, \\
7 & 18 & Added the sweepings, cross cutting was performed and mixed well. \\
8 & 20 & Added all the other ingredients slowly and repeated the step No 7. \\
9 & 25 & Took out as a sheet and rolled it and passed it through tight nip rollers for five times. \\
10 & 30 & Finally took out as a sheet. \\
\hline
\end{tabular}


Appendix 4: Preparation of chlorinatedpolyethylene (CM) master-batch

\begin{tabular}{lcl}
\hline $\begin{array}{l}\text { Step } \\
\text { No }\end{array}$ & $\begin{array}{c}\text { Time elapsed } \\
\text { Min }\end{array}$ & Action \\
\hline 1 & 0 & Added CM, \\
2 & 2 & Added $1 / 3$ of FEF carbon black, \\
3 & 3 & Brushed down, \\
4 & 5 & Added further $1 / 3$ of carbon black, \\
5 & 7 & Added remaining $1 / 3$ of carbon black, \\
6 & 8 & Swept down, \\
7 & 10 & Dumped or discharged. \\
\hline
\end{tabular}

Appendix 5: Preparation of chlorinatedpolyethylene vulcanizate

\begin{tabular}{lll}
\hline $\begin{array}{l}\text { Step } \\
\text { No } \\
\text { Min }\end{array}$ & \multicolumn{2}{l}{$\begin{array}{l}\text { Time elapsed } \\
\text { Action }\end{array}$} \\
\hline 1 & 0 & Added masterbatch and allowed for banding, \\
2 & 1 & Added SBR rubber, \\
3 & 2 & Cross cutting was performed each side for six times, \\
4 & 4 & Added zinc borate and antimony oxide, \\
5 & 5 & Freely ran the rollers for 2mins, \\
6 & 7 & Crosscutting was performed on each side for five times, \\
7 & 8 & Added Flectol H and Magnafin, \\
8 & 9 & Ran the rollers for 2mins and crosscutting was performed, \\
9 & 11 & Finally added DCP and MgO, \\
10 & 12 & Crosscutting was performed on each side for five times, \\
11 & 13 & Dispatched and secured in a polythene. \\
\hline
\end{tabular}

